Journal of Engineering and Applied Sciences 14 (Special Issue 7): 10152-10155, 2019

ISSN: 1816-949X

(C) Medwell Journals, 2019

\title{
Preparation and Characterization of Acid Resistant Rubber Composites Reinforced with Nano Silica
}

\author{
${ }^{1}$ Fadhel Abbas Hadi and ${ }^{2}$ Rheam G. Kadhim \\ ${ }^{1}$ Department of Physics of Materials, State Company of Rubber Industry and Tires, Najaf, Iraq \\ ${ }^{2}$ Department of Physics, College of Science, University of Babylon, Babylon, Iraq
}

\begin{abstract}
The natural rubber has good resistance for some acids such as hydrochloric acid. Therefore, natural rubber composites are used in the lining of acid containers. Acid resistance of the natural rubber can be improved by types and levels of fillers. This research studies the effect of silica nanoparticles on acid resistance of natural rubber composites for (37\% w/w) hydrochloric acid. Six rubber compounds were prepared with various levels of nano silica of $0,1,2,3,4,5$ (parts per hundred parts of rubber weight).Tensile properties, hardness (Shore A), compression set, tear resistance and abrasion resistance were tested. Test specimens of tensile properties were immersed in hydrochloric acid for $70 \mathrm{~h}$ at room temperature. After immersion, they were dried and tested for determining acid resistance. The acid resistance of rubber composites improved by the addition of nano silica and the best acid resistance of rubber composite was gotten at 3 .
\end{abstract}

Key words: Nano silica, natural rubber, acid resistance, hydrochloric acid, determining, immersion

\section{INTRODUCTION}

Corrosion occurs because of the chemical reaction between a metallic surface and its environment. When the metal surface is in contact with the acid, the metal such as iron is attacked or dissolved and hydrogen is evolved as a gas. The corrosion of metals can also occur in freshwater, seawater, salt aqueous solutions, alkaline aqueous solution and gases. The anti corrosive is very important to protect most products of modern technology (Roberge, 2000).

One of the best ways to treat this problem is the lining of the surface of equipment by rubber composites but the types of rubber don't have the same chemical resistance. The natural rubber has low resistance to ozone but butyl rubber has excellent resistance too zone. Therefore, it must choose a suitable rubber for lining (Schweitzer, 2006).

The chemical resistance of rubber can be improved by the addition of fillers. Ji-Fang et al. added nano alumina to natural rubber for improving chemical resistance against hydrochloric acid aqueous solution and sodium hydroxide aqueous solution (Fu et al., 2012). Mohammed et al. (2017) added barium sulfate to natural rubber for improving chemical resistance against hydrochloric acid aqueous solution. Chukov et al. (2018) used carbonization of Nitrile Butadiene Rubber (NBR) by different carbon fillers, graphite, shungite fillers, carbon black and silicon carbide for improving the chemical resistance of nitrile butadiene rubber composites which are used in the industry of oil pump impellers.
Nano silica plays an important role in improving the mechanical properties and chemical resistance of rubber composites through filler-rubber interaction (Thomas et al., 2013; Anand et al., 2015).

Nano silica is widely used as reinforcing filler because it has a high specific surface area and small particle size. Silica nanoparticles tend to agglomeration due to filler-filler reaction is greater than filler-rubber reaction. Therefore, the dispersion of silica particles is not homogeneous inside the rubber. The coupling agent is added to rubber composites for incorporating silica with rubber. It has a Silanol group (Si-O-H) for creating bonds between polymer chains and silica particles and preventing the accumulation of silica nanoparticles. Therefore, the presence of the coupling agent facilitates the dispersion of nano silica particles inside rubber composites during the compounding process. Nano silica is added to rubber as a unique filler or added with carbon black as dual filler. Many studies include the addition of nano silica with small amounts ( $<4 \%$ of the total weight of rubber compound) to avoid the agglomeration of silica particles (Rajkumar et al., 2013; Abitha and Vasudev, 2014; Ahmed et al., 2015; Sultani et al., 2017). Acid resistance of rubber composites can be determined by the following equation (ASTM, 1998):

$$
\Delta \mathrm{P} \%=\frac{\mathrm{P}_{\mathrm{i}}-\mathrm{P}^{\circ}}{\mathrm{P}^{\circ}} * 100
$$


J. Eng. Applied Sci., 14 (Special Issue 7): 10152-10155, 2019

Where:

$\mathrm{P}_{\mathrm{i}}=$ The Property such as tensile strength (after immersion)

$\mathrm{P}^{\circ}=$ The Property (before immersion)

$\Delta \mathrm{P}=$ The change rate of the Property due to the immersion

Acid resistant rubber composites are prepared according to specifications of mechanical properties. These specifications are prepared by companies of rubber lining such as HAW Linings GmbH or scientific societies such as ASM International (American Society for Metals).These mechanical properties are certified for the acceptability of acid resistant rubber composites (Cramer and Covino Jr., 2003).

\section{MATERIALS AND METHODS}

Natural rubber (SVR5 produced by Hoa Thuan CO. Vietnam), conventional zinc oxide (purity $=99 \%$, particle size $=0.5-1 \mu \mathrm{m}$ and surface area $=3-5 \mathrm{~m} 2 / \mathrm{gm}$, produced by Chem TAL Sunnyjoint Chemicals CO. China), CTP100 (produced by Shenyang Sunnyjoint Chemicals CO. China), carbon black (Type N326, Iran Carbon CO. Iran), paraffinic oil (Daura Refinery, Iraq), MBTS (Al-Kiiubar CO. KSA), sulfur (Al-Meshrak CO. Iraq), TMQ (Shenyang Sunny joint Chemicals CO. China), 6PPD (Shenyang Sunny joint Chemicals CO. China), stearic acid (Acidchem-International CO. Malaysia), nano silica treated with silane coupling agent (purity $=99 \%$, particle size $=10-30 \mathrm{~nm}$, surface area $=400 \mathrm{~m}^{2} / \mathrm{gm}$, coupling agent is Y-methacry loxypropyl trimethoxy silane (KH-570), Skyspring Nanomaterials, Inc. USA).

Compounding: Compounding of rubber and additives carried out in state company for rubber industry and tires in Najaf and according to ASTM D3182. Compounds were prepared by mill mixing on a laboratory $(300 \times 150 \mathrm{~mm})$ two roll mill. Compound recipes are listed in Table 1 with different levels of nano silica.

Characterization: Mechanical properties were selected according to specifications of ASM International documents. Modulus at $300 \%$ was tested instead of modulus at $100 \%$ due to it is certificated in most studies of rubber composites (Cramer and Covino Jr., 2003).

Tensile properties were tested according to ASTM D412 and tear resistance was tested according to ASTM D 624 by Monsanto T10 Tensometer. Hardness was tested according to ASTM D2240 by durometer at scale shore (A).

Abrasion resistance was tested according to ASTM D 3389. Compression was tested according to ASTM D575 and the time period of the test was $24 \mathrm{~h}$.
Table 1: Recipes of rubber compounds

\begin{tabular}{lllllll}
\hline Materials & A1 & A2 & A3 & A4 & A5 & A6 \\
\hline SVR5 & 100 & 100 & 100 & 100 & 100 & 100 \\
Nano zinc & 2 & 2 & 2 & 2 & 2 & 2 \\
oxide & & & & & & \\
Stearic acid & 2 & 2 & 2 & 2 & 2 & 2 \\
TMQ & 1.5 & 1.5 & 1.5 & 1.5 & 1.5 & 1.5 \\
6PPD & 1.5 & 1.5 & 1.5 & 1.5 & 1.5 & 1.5 \\
Carbon black & 45 & 45 & 45 & 45 & 45 & 45 \\
N326 & & & & & & \\
Nano silica & 0 & 1 & 2 & 3 & 4 & 5 \\
Paraffinic oil & 3 & 3 & 3 & 3 & 3 & 3 \\
MBTS & 1.2 & 1.2 & 1.2 & 1.2 & 1.2 & 1.2 \\
Sulfur & 3.25 & 3.25 & 3.25 & 3.25 & 3.25 & 3.25 \\
CTP-100 & 0.4 & 0.4 & 0.4 & 0.4 & 0.4 & 0.4 \\
\hline
\end{tabular}

Specimens of tensile properties were immersed inside $(37 \% \mathrm{w} / \mathrm{w})$ hydrochloric acid for $70 \mathrm{~h}$ at room temperature according to ASTM D471. After immersion, they were dried and tested for getting acid resistance.

\section{RESULTS AND DISCUSSION}

Mechanical properties: Figure 1-3 show the effects of nano silica level on tensile strength, modulus at $300 \%$ and tear resistance, respectively. Tensile strength and tear resistance tend to increase by increasing of nano silica level up to $3 \mathrm{phr}$ and decrease after this level but modulus at $300 \%$ tends to increase by increasing of nano silica level up to $4 \mathrm{phr}$ and decreases after this level.

The increasing of tensile strength, modulus at $300 \%$ and tear resistance by increasing of nano silica level due to filler-rubber interaction. This interaction occurs between silica nanoparticles and polymer chains of rubber and it increases by increasing of nano silica level (Rajkumar et al., 2013; Abitha and Vasudev, 2014; Sultani et al., 2017). Tensile strength and tear resistance decrease after 3 phr but modulus at 300\% decreases after $4 \mathrm{phr}$ by increasing of nano silica level due to the agglomeration of silica nanoparticles. The agglomeration reduces the role of nano silica in reinforcing rubber composites and thus reduces the mentioned mechanical properties (Lay et al., 2013; Peng et al., 2007).

Figure 4 shows the effect of nano silica level on elongation at break. It increases by increasing of nano silica level due to barriers that are created bysilica nanoparticles between polymer chains during the vulcanization. Barriers of silica nanoparticles preventthe creating of crosslinks between polymer chains. Therefore, the increasing amount of nano silica reduces crosslink density and thus increases elongation at break (Rajkumar et al., 2013).

Figure 5 shows the effect of silica nanoparticles loading on hardness. The hardness increases by increasing of nano silica level. The gradual increasing of hardness refers to that the vulcanization at higher temperatures increases the cross link density. Whereas in this research, test specimens of hardness are cured at higher temperatures in comparing the curing temperature of test specimens of tensile properties and tear resistance. 


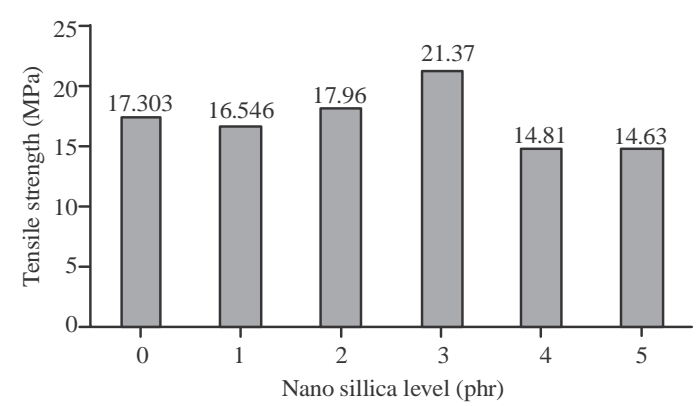

Fig. 1: Influence of nano silica level on tensile strength

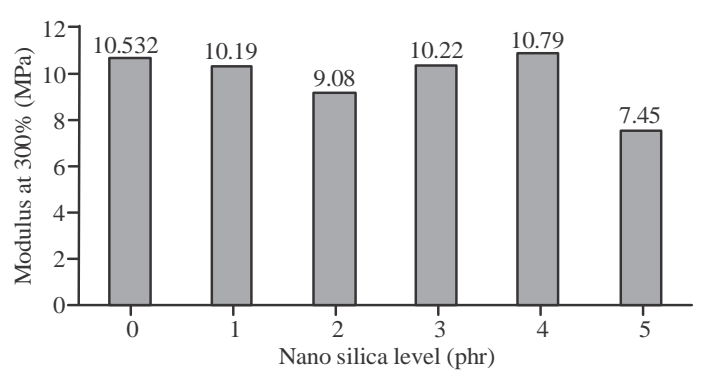

Fig. 2: Influence of nano silica level on modulus at 300\%

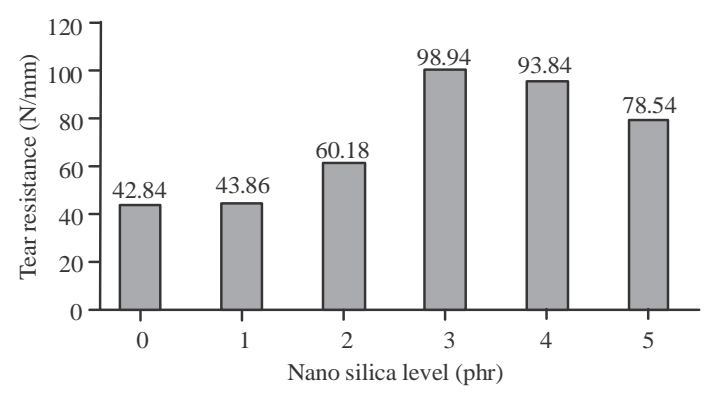

Fig. 3: Influence of nano silica level on tear resistance

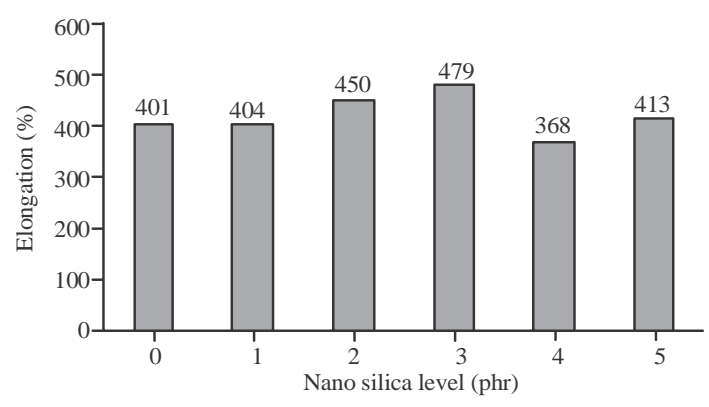

Fig. 4: Influence of nano silica level on elongation

Therefore, the agglomeration of silica nanoparticle doesn't decrease the hardness (Rajkumar et al., 2013; Abitha and Vasudev, 2014).

Figure 6 shows the effect of nano silica level on abrasion loss, it increases by increasing of nano silica level. Thus, abrasion resistance decreases due to the

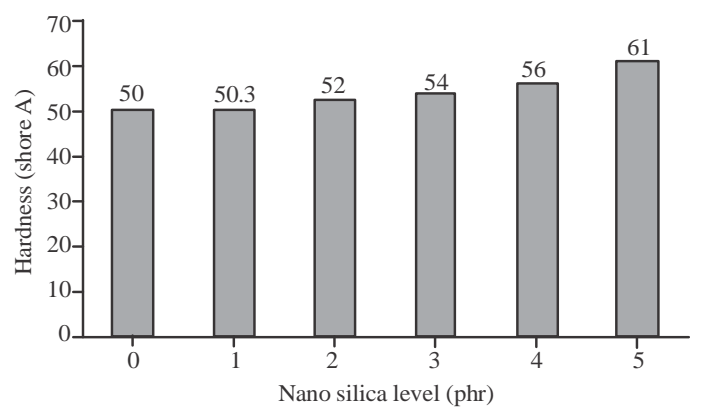

Fig. 5: Influence of nano silica level on hardness

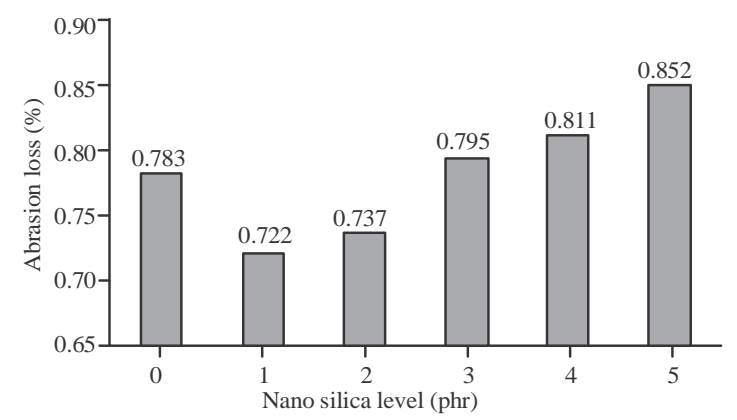

Fig. 6: Influence of nano silica level on abrasion loss

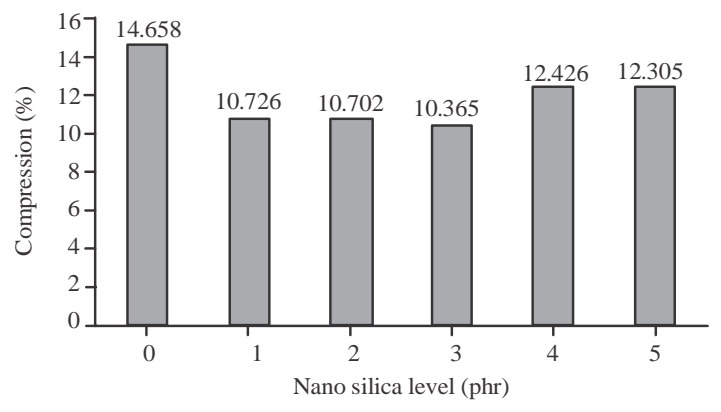

Fig. 7: Influence of nano silica level on compression

agglomeration of silica nanoparticles but $1 \mathrm{phr}$ of silica nanoparticles gives the best abrasion resistance with the lowest abrasion loss (Ahmed et al., 2015).

Figure 7 shows the effect of nano silica level on compression, it decreases by increasing nano silica level down to $3 \mathrm{phr}$ and increases after that. Decreasing of compression occurs because of nano silica-rubber interaction. After minimum value, agglomeration of silica nanoparticles increases compression (Sultani et al., 2017).

Acid resistance: Figure 8 shows the effect of nano silica level on acid resistance of natural rubber composites. The acid resistance was measured by immersion of tensile specimens inside (37\% w/w) hydrochloric acid and studied change rates of tensile properties due to immersion. Change rates of tensile strength, modulus at $300 \%$ and elongation at break have negative value at 


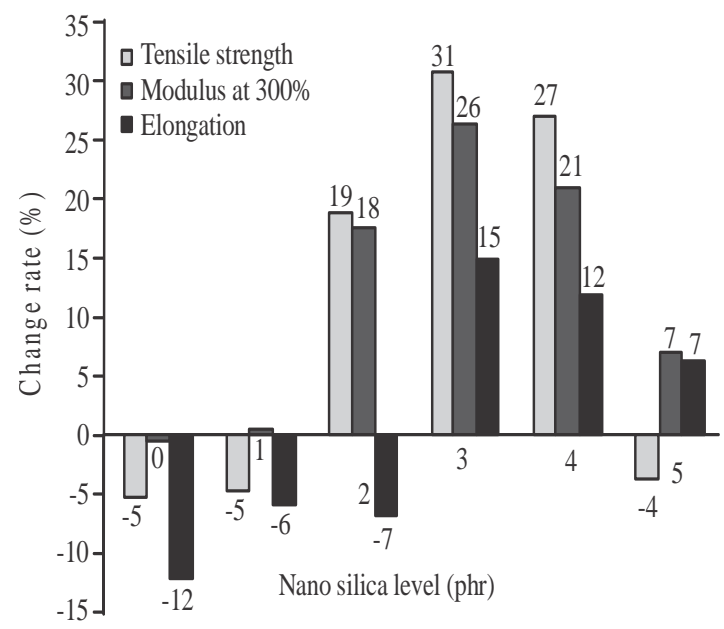

Fig. 8: Influence of nano silica level on the change rate of tensile properties

$0 \mathrm{phr}$ but tensile strength has positive value at $2 \mathrm{phr}$ and it increases by increasing of nano silica level up to $3 \mathrm{phr}$ and decreases after that. Modulus at $300 \%$ has positive value at $1 \mathrm{phr}$ and it increases by increasing of nano silica level up to $3 \mathrm{phr}$ and decreases after that. Elongation at break has negative values at 0,1 and $2 \mathrm{phr}$ but it increases and has a higher positive value at $3 \mathrm{phr}$ and decreases after that. The increasing in change rates of tensile properties is due to the role of nano silica in improving the degradation resistance and filler-rubber interaction. After $3 \mathrm{phr}$, the agglomeration of silica nanoparticles reduces the role of nano silica in improving acid resistance (Anand et al., 2015).

\section{CONCLUSION}

The addition of a small quantity of nano silica to rubber composite with carbon black improves mechanical properties and acid resistance of natural rubber composites. The best mechanical properties and best acid resistance can be given by the addition of $3 \mathrm{phr}$ of nano silica. Mechanical properties of natural rubber composites at $3 \mathrm{phr}$ of nano silica are in the ranges of ASM specifications.

\section{REFERENCES}

STM., 1998. ASTM D471-98e2: Standard test method for rubber property-effect of liquids. ASTM International, West Conshohocken, Pennsylvania, USA. https://www .astm.org/DAT ABASE.CART/HISTORICAL/D471-98E2.htm

Abitha, V.K. and A.R. Vasudev, 2014. Effect of nanosilica on air permeability of natural rubber automotive tube compound. J. Nat. Rubber, 66: 1-10.
Ahmed, J.K., M.H. Al-Maamori and H.M. Ali, 2015. Effect of nano silica on the mechanical properties of Styrene-Butadiene Rubber (SBR) composite. Intl. J. Mater. Sci. Appl., 4: 15-20.

Anand, K., S. Varghese and T. Kurian, 2015. Degradation behaviour of Nano Silica and Nano Titania filled natural rubber latex nanocomposites. Rubber Sci., 28: 294-304.

Chukov, D.I., A.A. Stepashkin, A.I. Salimon, D.S. Kaloshkin and I.S. Pyatov, 2018. Mechanical properties and chemical resistance of new composites for oil pump impellers. Appl. Sci., 8: 1-7.

Cramer, S.D. and B.S. Covino Jr., 2003. Corrosion: Fundamentals, Testing and Protection. 10th Edn.,/Vol. 13A, ASM International Publisher, Ohio, USA., ISBN:9780871707055, Pages: 1135.

Fu, J.F., L.Y. Chen, H. Yang, Q.D. Zhong and L.Y. Shi et al., 2012. Mechanical properties, chemical and aging resistance of natural rubber filled with nano- $\mathrm{Al}_{2} \mathrm{O}_{3}$. Polym. Compos., 33: 404-411.

Lay, M., A.R. Azura, N. Othman, Y. Tezuka and C. Pen, 2013. Effect of nanosilica fillers on the cure characteristics and mechanical properties of natural rubber composites. Adv. Mater. Res., 626: 818-822.

Mohammed, R., B. Reddy, K. Sridhar and M.P. Khan, 2017. Preparation and characterization of rubber lining material for $33 \%$ diluted HCL acid storage tank. Intl. J. Mod. Trends Sci. Technol., 3: 93-97.

Peng, Z., L.X. Kong, S.D. Li, Y. Chen and M.F. Huang, 2007. Self-assembled natural rubber/silica nanocomposites: Its preparation and characterization. Compos. Sci. Technol., 67: 3130-3139.

Rajkumar, K., P. Ranjan, P. Thavamani, P. Jeyanthi and P. Pazhanisamy, 2013. Dispersion studies of nanosilica in NBR based polymer nanocomposite. Rasayan J. Chem., 6: 122-133.

Roberge, P.R., 2000. Handbook of Corrosion Engineering. McGraw-Hill Professional, New York, USA., ISBN-13: 9780070765160, Pages: 1072.

Schweitzer, P.A., 2006. Corrosion of Polymers and Elastomers. 2nd Edn., CRC Press, Boca Raton, Florida, USA., ISBN:9780849382451, Pages: 592.

Sultani, A.K., S.H. AL-Nesrawy and M.H. Al-Maamori, 2017. Reinforcement effect of nano silica on tensile set properties of the tire side wall batch. J. Chem. Pharm. Sci., 10: 1545-1550.

Thomas, S., C.H. Chan, L.A. P othen, J. Joy and H.J. Maria, 2013. Natural Rubber Materials Volume 2: Composites and Nanocomposites. Royal Society of Chemistry (RSC) Publishing, Cambridge, UK., ISBN:978-1-84973-631-2, Pages: 830. 